Proceedings of the 2011 Winter Simulation Conference

S. Jain, R. R. Creasey, J. Himmelspach, K. P. White, and M. Fu, eds.

\title{
MODELING SUPPLY CONTRACTS IN SEMICONDUCTOR SUPPLY CHAINS
}

\author{
Konstanze Knoblich \\ Hans Ehm \\ Infineon Technologies AG \\ Am Campeon 1-12 \\ Neubiberg, 85579, GERMANY
}

\author{
Cathal Heavey \\ Peter Williams \\ Enterprise Research Centre \\ University of Limerick \\ Ireland
}

\begin{abstract}
Semiconductor manufacturers face high demand uncertainty due to volatile and rapidly changing technology development as well as inaccurate customer forecasts. The paper first presents a description of contract clauses used in semiconductor supply chains, obtained through a literature review and a field study. The paper then presents a review of the literature on studies in supply chain contracts focusing on flexibility contracts and capacity option contracts. Finally, the paper presents models to study contract flexibility and capacity reservation options for a semiconductor manufacturer supplier and a buyer. The purpose of the models is to compare a representative standard flexibility contract currently used in semiconductor supply chains and a capacity options contract.
\end{abstract}

\section{INTRODUCTION}

In the past as well as today the semiconductor industry faces extreme variability on capacity utilization. Economic cycles, the permanent progress in innovation and the reduction of product life cycles are the main factors in this volatility. Effective planning and utilization of production capacities in semiconductor manufacturing has significant impact on the operational profitability of this sector. Semiconductor manufacturers typically segment capacity management into long term strategic planning and operational planning. Long term planning relates to managing production capacity investment in order to fulfill long term future market demands. Operational planning is concerned with matching available supply with the customer demand and if necessary to adjust and reconfigure the production plan.

While capacity management and allocation are important decisions for any manufacturing industry, there are a few factors that make this problem especially important for the semiconductor industry. The high level of investment costs and the long lead times for new facility development makes capacity planning decisions challenging and risk prone. An incorrect investment decision (over or under estimation) can have huge impact on the profitability of a company. The manufacturer's internal aggregated capacity forecast, used during strategic planning is an approximation of the future customer orders, which are on a higher granularity. The effective manufacturer capacity depens on how the capacity is planned to be used (e.g., which facility, technology mixtures, product mix). Also, the permanent progress in innovation (e.g. smaller line width) intensifies this situation. Due to these characteristics it is common to share unconstrained demand forecasts in the semiconductor supply chain in order to improve capacity planning. However, demand forecasts can have a high level of inaccuracy, especially long term demand forecasts, with a resulting risk to the semiconductor manufacturing in managing capacity. Also, outsourcing of production is a strategy to reduce risk that has been widely adopted in the semiconductor sector in recent years.

In this paper models are described for the analysis of supply chain (SC) contracts in the semiconductor sector. Specifically, the paper describes models for the analysis of two types of contracts: a contract with rescheduling, quantity flexibility and cancellation clauses and a capacity option contract. The next section describes contract clauses used in semiconductor SC contracts, obtained from a study of SC contracts in a 


\section{Knoblich, Ehm, Heavey, and Williams}

case study semiconductor manufacturer. This is followed by Section 3 which provides a short review of past studies on contracts with flexibility clauses and capacity option contracts. Section 4 provides a description of models proposed for SC contract analysis. Finally, conclusions and further work are described.

\section{FIELD STUDY}

To understand better the contract clauses used in the semiconductor sector, the contract clauses used in a case study company were documented and mapped onto classifications found in the literature. In Tsay, Nahmias, Agrawal, Tayur, Ganeshan, and Magazine (1999) a classification of contract clauses used in SC is described. In the case study company contract clauses given in Tsay, Nahmias, Agrawal, Tayur, Ganeshan, and Magazine (1999) were observed, such as, decision rights, pricing, minimum purchasing commitments, quantity flexibility, buyback or returns policies, allocation rules, lead time and quality. Further clauses were also found in the case study company such as, demand signal, rescheduling, stock and run rate. Products in the case study, as typically found in the semiconductor sector, were classified into Commodity, Application Specific Standard Products (ASSP), Customer Specific Products (CSP) and End of Life (EOL) products. Below is a summary of contract clauses found in the case study company, used across the different product types, to govern the operation of the SC between buyer and seller.

- Decision Rights - If the contract specifies decision rights, a manufacturer for example can exert direct control over a retailer. For example, the manufacturer can dictate the retailer's order size or the retail price under a Resale Price Maintenance (RPM) agreement.

- Pricing - The pricing determines how transactions between the two contract parties translate into financial streams. For example, the wholesale price can be written as $w(q)=F+q t$ for an order quantity $q$, where $F$ is the fixed cost and $t$ the variable cost factor. For $F=0$ the wholesale price contract results in a linear pricing. For a positive $F$, this wholesale price contract is called a two part tariff because it includes both a fixed payment and a variable payment. In other situations, quantity discounts are possible for high order quantities or the manufacturer can subsidize the retailers if their inventory loses value. This is frequently used in price protection agreements (Lee, Padmanabhan, Taylor, and Whang 2000) that are prevalent in the personal computer industry, as described in Callioni, de Montgros, Slagmulder, Van Wassenhove, and Wright (2005) for an example at HP. Lariviere and Porteus (2001) also study price only contracts in a newsvendor setting. They show that a lower coefficient of variation leads to a higher wholesale price.

- Minimum Purchasing - The minimum purchasing clause determines the minimum quantity of a product, which a customer will buy from a supplier. Common examples can be found in the high tech industry, especially in the semiconductor industry, where a customer has to commit to a certain quantity because the supplier has to build up capacity well in advance (Cachon 2004).

- Quantity Flexibility - this contract clause allows one of the parties to deviate from an initially committed quantity. For example, a customer wants to change his previously committed purchasing quantity of a component because additional knowledge of demand has become available. How much and at what cost a supply chain partner can deviate from the initially quantity is determined by a quantity flexibility contract (Tsay 1999)

- Cancellation - The cancellation clause defines the customers liability in the case that the deviation of the updated demand information to the initially committed quantity is beyond what is defined in quantity flexibility and rescheduling contract clauses.

- Buyback or Return Policies - With this contract clause, the customer can return unsold products to the supplier. Pasternack (1985) shows that the supply chain can be coordinated with a buyback contract if the supplier has infinite capacity.

- Allocation - The allocation clause specifies how the supplier's inventory is distributed among its customers when there is tight or insufficient supply compared to customer demand. 


\section{Knoblich, Ehm, Heavey, and Williams}

- Lead Time - With this clause, the lead time can be specified as either a fixed constant or a random variable. For example, Dell requires immediate availability (JIT - just in time) of components from its suppliers (Kapuscinski, Zhang, Carbonneau, and Moore 2004) or a company can specify a time-window (JIS - just in sequence) in which deliveries should arrive. This contract clause is often connected with a pricing clause as for example in Cachon and Zhang (2006) where a manufacturer has to pay late fees if the product is not immediately available.

- Demand Signal - this contract clause determines the method and the granularity of the shared demand information between the customer and the supplier. For example, it could be used to define that the customer has to provide the supplier with weekly updated unconstrained forecast of estimated future demand for the next 12 months via EDI (Electronic Data Interchange). Furthermore, if there does not exist a binding period in the forecast horizon the customer has to change the forecast into a purchase order to trigger product delivery.

- Rescheduling - The rescheduling clause defines the customers flexibility to change the order quantity, to cancel or to reschedule an already confirmed forecast or order. Rescheduling means that the customer can prepone - or postpone forecasts or orders compared to the initial confirmed delivery date.

- Stock - The stock clause specifies what kind of stock management will be practiced between customer and supplier. For example a retailer managed inventory (RMI) in which the customer controls the inventory decisions or vendor managed inventory (VMI), in which the supplier has the control.

- Run Rate - This contract clause defines a special delivery arrangement in which the supplier will deliver the customer on an agreed frequency without attending the corresponding order or forecast, in order to reduce the lead time. The Run Rate Quantity for commodities is generally based on the customer's last forecast of, for example, the last quarter and will be defined between supplier and customer and is firm for the duration of, for example, one quarter.

The above lists the range of contract clauses used in semiconductor SC. This paper describes models used to evaluate the effectiveness of different contract clauses in capacity planning. Specifically, a contract that uses a rolling quantity flexibility, rescheduling and cancellation clauses will be compared with a contract with a capacity option clause. The next section will provide a focused review of studies on these type of contracts.

\section{LITERATURE REVIEW}

Supply chain contracts have been studied extensively in the context of conventional supply chains. However, there are several unique characteristics that make semiconductor supply chains differ from supply chains generally studied within the literature. Semiconductor supply chains have long cycle times, they are capital intensive with long investment cycles, to keep unit cost low utilization of capital equipment needs to be high, products tend to have short product lifecycles, demand is highly volatile and forecasting can have low accuracy (Katircioglu and Gallego (2011)). The following parts will focus on quantity flexibility contracts and option contracts.

\subsection{Quantity Flexibility Contracts}

Flexible supply contracts are used where demand uncertainty exists, allowing a customer to modify order quantities/prices. Flexibility can be both, a hedge against negative outcomes, but it can also be used to maintain the probability associated with positive outcomes. For example, a flexibility clause can be beneficial to a customer in the case of overestimated demand and he prefers a lower delivery quantity rather than his initial order, or in the case of a low spot price when he underestimated the demand and he prefers to purchase additional products on the spot market rather than from his contracted supplier. 


\section{Knoblich, Ehm, Heavey, and Williams}

Quantity flexibility contracts specify rules for the buyer on order quantity changes. Anupindi (1998) analyse supply quantity flexibility agreements for multiple products with stochastic demands and business volume discount. They defined rolling horizon flexibility contracts as a quantity flexibility contract updated each time period over a time horizon. A detailed analysis of quantity flexibility contracts is carried out by Tsay, Nahmias, Agrawal, Tayur, Ganeshan, and Magazine (1999). The authors state that the quantity flexibility contract is a method for material and information flow coordination in a supply chain with rolling horizon planning. They investigate the incentives for which a buyer and seller would participate in a quantity flexibility contract, that is, would a buyer be willing to commit to a certain order quantity for a lower price, and would the seller derive benefits from certainty of sales and thus be willing to give a discount. Walsh, Williams, and Heavey (2008) analyse how to minimize the impact of demand uncertainty in a discrete event simulation model. The authors study two types of contracts, one with constant flexibility bounds and the other with a decreasing flexibility bound in the supply chain setting with an OEM and a contract manufacturer. They state that the both contracts increase the fill rate performance, attenuate the bullwhip effect and reduce the inventory for both OEM and CM. Lian and Deshmukh (2009) study rolling horizon planning with quantity flexibility. The authors develope an analytical model in order to characterize the optimal replenishment policies from the buyers perspective.

Li and Kouvelis (1999) study contract flexibility in time and quantity for deterministic demand and price uncertainty. This contract allows the buyer to specify the order quantity over a given time horizon without specifying the exact delivery date. In the context of the fashion apparel industry Eppen and Iyer (1997) model a quantity flexibility contract which includes a backup agreement. The buyer places his order before the selling season and the manufacturer delivers only a part of the initial order quantity. After two weeks, the buyer can decide if he wants to receive the remainder of the original order or just a part of it. The manufacturer will charge the buyer a penalty cost for each undelivered unit.

\subsection{Option in Supply Chain Contracts}

The options used in supply contracts normally provide the right, but not the obligation to receive (call option) or deliver (put option) a product or service by a certain time and predetermined price. For a supplier selling raw material to a buyer Cheng, Ettl, Lin, Schwarz, and Yao (2002) model a flexible supply contract in which the buyer is required to firmly commit to one part of the order quantity and purchases options on the remainder. Furthermore they derive the optimal number of options to purchase and show that channel coordination can be achieved when the contracting parties negotiate over profit sharing and assuming that the base price and the quantity of the firmly committed order part are given. Similarly, Barnes-Schuster, Bassok, and Anupindi (2002) investigate supply contracts with options in a two period model. The customer can operate in two different production modes: lower purchase cost with a longer lead time and a high purchase cost with a short lead time. van Delft and Vial (2004) programmed a stochastic model based on the Barnes-Schuster, Bassok, and Anupindi (2002)'s model that allows the numerical analysis for various contractual parameters.

Kleindorfer and $\mathrm{Wu}$ (2003) survey the theory and the practice of the use of options in B2B exchanges and investigate how options have been used to integrate long and short term contracting. The emergence of electronic market platforms such as B2B exchanges that enable last minute spot market purchases has recently confirmed the trend towards combining different procurement forms. The authors provide a framework (see Figure 1), that explains the structure of existing B2B exchanges with regard to the predominate contract form used, based on the cost of assuring the ability of codifiability (which means the ability to electronically specify product, delivery, and settlement requirements in a verifiable manner), the difference in production costs between spot and contract based sales, the cost of establishing or using contract relationships and the mixture of contract and spot markets used in an electronic B2B exchange.

Electronic marketplaces can also be used for supply option contracts as a platform for secondary markets (Lee and Whang (2002)), in which an option buyer can sell unused options to other buyers. 
Knoblich, Ehm, Heavey, and Williams

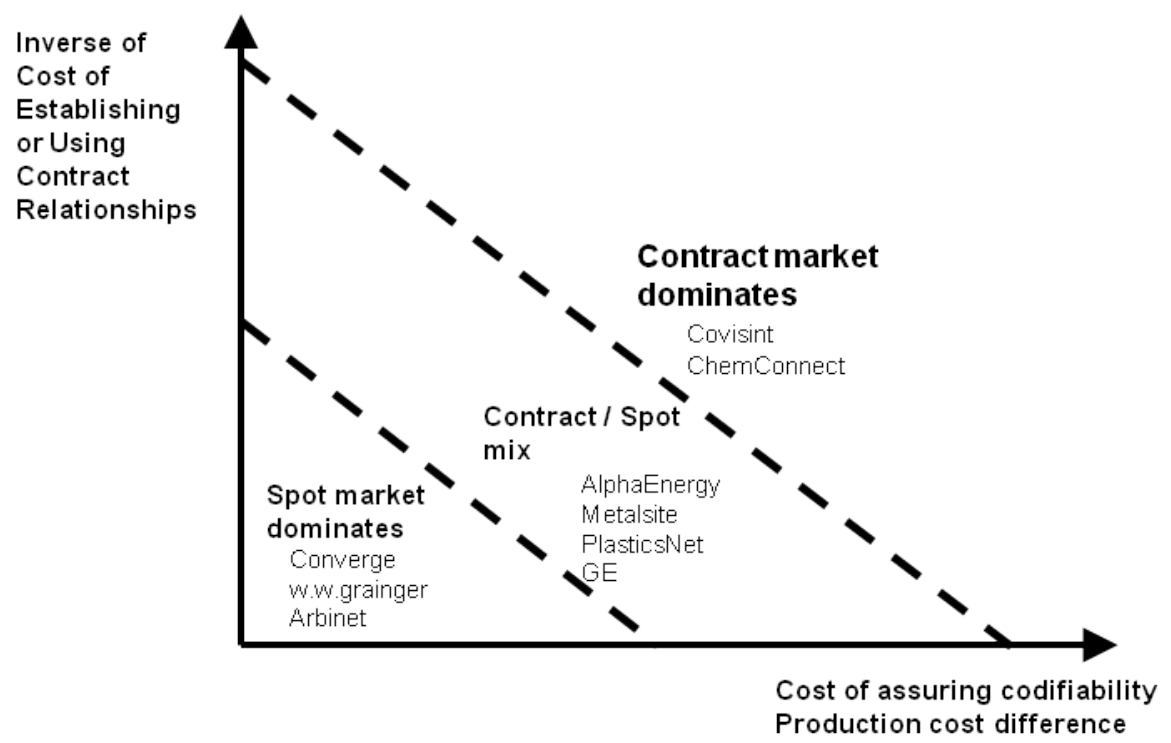

Figure 1: Classification of B2B exchange and contracting including company examples [Kleindorf and Wu (2003)].

Analogue to mixing short and long term contracting strategies, Martinez-de Albeniz and Simchi-Levi (2005) show how a manufacturer can increase his expected profit and reduce his financial risk by using a portfolio approach for procurement contracts consisting of a combination of fixed commitment contracts, option contracts and spot market purchases. Furthermore, Martinez-de Albeniz and Simchi-Levi (2009) develop a formulation for option contracts for competition in the electricity market with one buyer and many suppliers. Wu, Kleindorfer, and Zhang (2002) study the coordination and option price problem, with a two-part contract fee structures (reservation fee and execution fee). They investigate a bidding strategies in the presence of a long term contract market and a short term spot market with market risk in the form of spot price uncertainty and assuming demand and cost as deterministic, for capital intensive production of non-storable products such as air cargo transportation services. They model the problem as a Stackelberg game with the seller as leader. They derive the optimal contracting strategy from the buyers point of view and the optimal bidding strategies from the suppliers side.

$\mathrm{Wu}$ and Kleindorfer (2005) extend the model presented in Wu, Kleindorfer, and Zhang (2002) by considering multiple suppliers and random spot market price. Their model uses a price and quantity dependent demand function. Edin and Hermalin (2000) present option contracts designed to evaluate the agent-principal problem (the agent principal problem is a conflict of interest and moral hazard issue between a principal and an agent which arises by performance specific duties that are in the best interest of the principal but may be costly, or not in the best interests of the agent) with a single product. Option contracts and renegotiation are used in order to prevent an undermining of the agent by the principal. Tan (2002) study the strategy of using capacity options in order to manage retailers demand volatility. The author finds that option-contracts can be used to manage demand variability. Furthermore the value of this strategy increases as the demand uncertainty increases. Schneeweiss, Zimmer, and Zimmermann (2004) present a special case where the supplier and not the customer has the option of not satisfying the quantity commitment. Therefore, the retailer will pay a bonus to the supplier if he meets the order quantity.

\section{MODEL DESCRIPTION}

Two different contracts between a buyer and a seller, described in Figure 2, are modeled in this study. The first contract, denoted the standard contract, is a representative supply contract found in the semiconductor 
Knoblich, Ehm, Heavey, and Williams

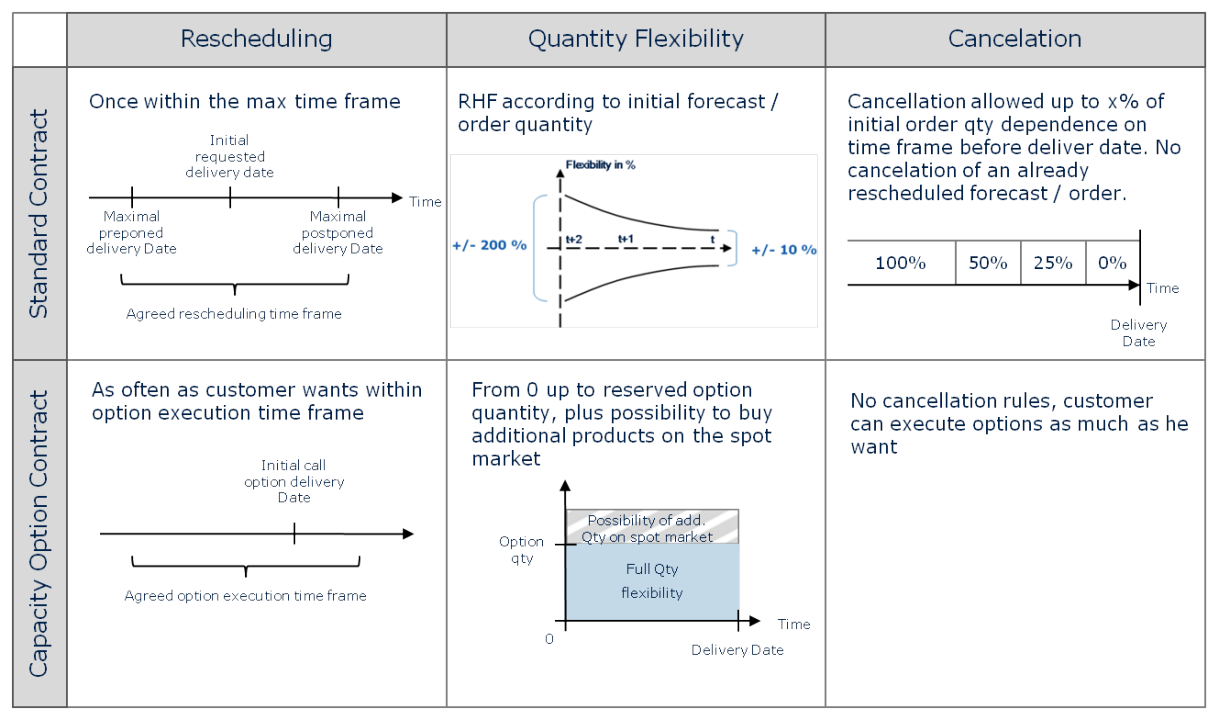

Figure 2: Comparison of flexibility rules.

sector. In this contract there are three operational clauses that govern the contract: (i) rescheduling clause that governs the flexibility given to the buyer to reschedule the timing of the delivery of the order; (ii) quantity flexibility that governs the changes in the quantity of the buyer order; (iii) a cancellation clause that governs order cancellations by the buyer. The objective is to compare this standard contract in semiconductor SCs to a capacity option contract. The capacity options contract requires buyers to purchase capacity options, for cost $p_{o}$, which can be executed within time period $o$ subject to delivery lead time constraints at cost $p_{e}$. If demand falls below the forecasted demand of the buyer incurs the option cost $p_{o}$, whilst if demand is greater than the forecasted demand the buyer can purchase from a spot market at cost $p_{s}$. In the capacity options contract there is no cancellation clause, see Figure 2.

The analysis in the contract market is limited to one supplier and one buyer. However, competition by other suppliers is included indirectly via the demand function. The extension of the model to multiple buyers is straightforward: The current single buyer can be interpreted as the aggregation of all buyers without changing the supplier's profit function. Initial demand, $D$, is assumed stochastic and there are no back orders. The supplier is assumed to have unlimited capacity, through internal and outsourced facilities, but capacity has a fixed lead time $L_{c}$. Within this lead time the supplier's capacity is fixed. In practice $L_{C}$ is in the range of 8-12 months. In the following, models to simulate these two contracts are described.

\subsection{Simulation Model Standard Contract}

In the standard contract the buyer provides forecasted demand for time period $T, L_{c}$ periods before the first scheduled delivery, $D D_{0}$ in planning period $T$. Based on the forecasted demand the supplier will source capacity to meet the aggregated demand for period $T$ (see Figure 3 )

The standard contract model consists of three supply chain operations contract clauses as shown in Figure 2. The first clause relates to rescheduling. Specifically the buyer has the flexibility to reschedule his initial delivery date $D D_{t}(t=0,1, \ldots, T)$ once within the time frame $D D_{t} \pm r$. The second clause is a RHF clause, which can be expressed as follows:

$$
\begin{aligned}
& \left(1-\gamma_{t j}^{L}\right) \cdot D_{j}^{t-1} \leq D_{j}^{t} \leq\left(1+\gamma_{t j}^{U}\right) \quad \text { when } \quad t \leq j \\
& D_{t}^{t}=D_{t} \quad \text { otherwise }
\end{aligned}
$$

where $D_{j}^{t}$ is the demand for period $j$ forecasted in period $t$. $\gamma_{t j}^{L}$ and $\gamma_{t j}^{U}$ denote the lower and upper flexibility bounds for period $j$ at period $t$, respectively. Based on this equation, demand can be adjusted by the 


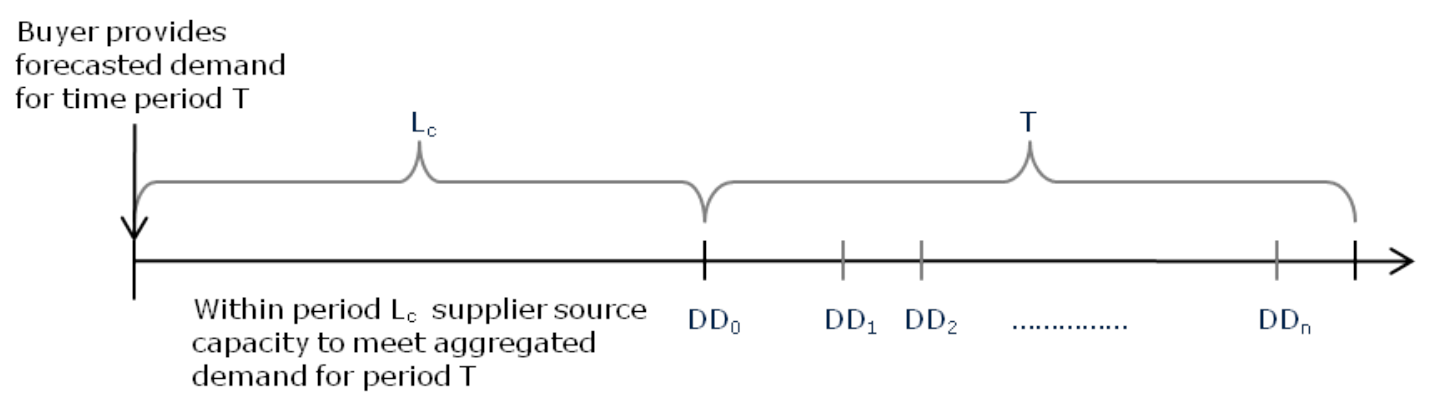

Figure 3: Capacity Planning.

buyer until until $t=j$ according to movements in market demand. When $j=t$, the demand is indicated as $D_{t}^{t}=D_{t}$ and is referred to as realized demand. The third clause in this contract is the cancellation clause, that permits order cancellations by a percentage $p$ within a specified time period, defined as $\left[i_{a}^{p}, i_{b}^{p}\right]$ defined over $T$, where $i_{a}^{p}, i_{b}^{p}$ define the start and end, respectively, of the period where $p$ percentage of an order can be canceled without a penalty.

Figure 4 describes the forecast process as observed in the semiconductor industry. The process starts with the buyer forecast demand provision to the supplier. The latter will check if the provided demand forecast is an initial or updated demand forecast of a previous version. The contract clauses will be applied on the updated demand forecast and a decision made to decline or accept the buyer update. In the case of an initial demand forecast, the supplier will check if the delivery date respects the product order lead time and will decide accordingly to accept or decline the forecasted demand request. When the order product order lead time is respected and the time between forecast entry and delivery date is longer than time period $L_{c}$ the supplier will always accept the buyer's request. Otherwise the supplier will only accept the demand request according to his capacity availability. When the supplier accepts the buyer forecast, he will reserve capacity according to the forecasted demand given. However, this process only reserves capacity, it does not trigger any delivery to the buyer. Furthermore, it can be the case, that the customer does not replace his forecast with a purchase order.

To trigger delivery the buyer has to send purchase orders. This process is described in Figure 5. After receiving customer purchase orders, the supplier will check the reserved capacity against the requested capacity of the purchase order and will apply accordingly the flexibility contract clauses. Should there be no previous demand forecast, the supplier will check if the product order lead time is respected and if the time between purchase order entry date and delivery date is longer or shorter than time period $T$ and will decide as in the forecast process.

\subsection{Simulation Model Option Based Contract}

In the capacity option model the buyer purchases capacity options from the supplier $L_{c}$ time periods before the first scheduled delivery, $D D_{0}$ in planning period $T$ at cost $p_{o}$ with an associated time window for option execution $o$. The option cost $p_{o}$ is a function of the time window $o$, i.e. the level of flexibility with the option. Using this information the supplier purchases capacity for planning period $T$. The buyer can exercise the option within the associated time window $o$ at cost $p_{e}$. If demand for the buyer exceeds its forecasted demand (expressed through the purchase of the capacity options), then the buyer can purchase from the spot market at cost $p_{s}$, with $p_{s}$ a function of component availability on the spot market. The spot market is supplied through the excess production of the supplier. When $p_{e}=0, p_{o}$ can be thought as the "wholesale" price and the contract between the buyer and the supplier as a fixed-commitment contract. When $p_{e}>0$, the contract can be seen as an option contract with a reservation fee of $p_{o}$ and an execution fee of $p_{e}$. When $p_{o}=0$ the contract can be seen as a wholesaler contract with non binding forecast. It 
Knoblich, Ehm, Heavey, and Williams

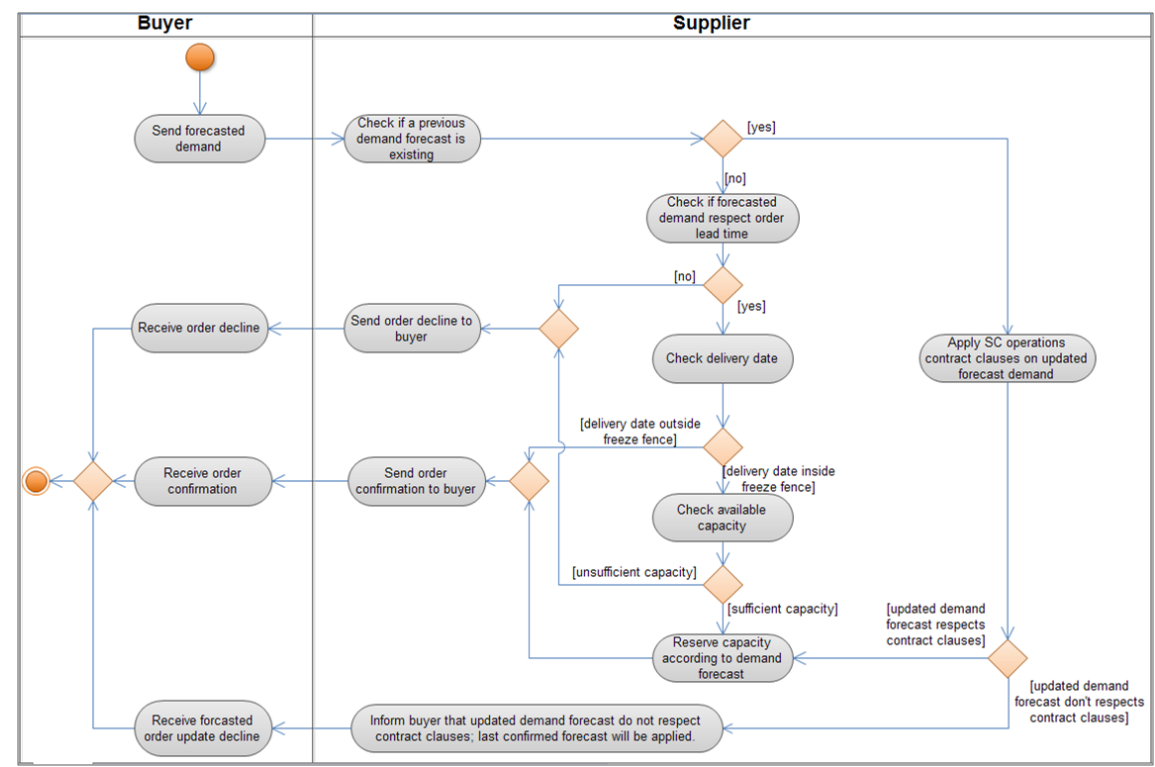

Figure 4: Current Status Model Forecast Process.

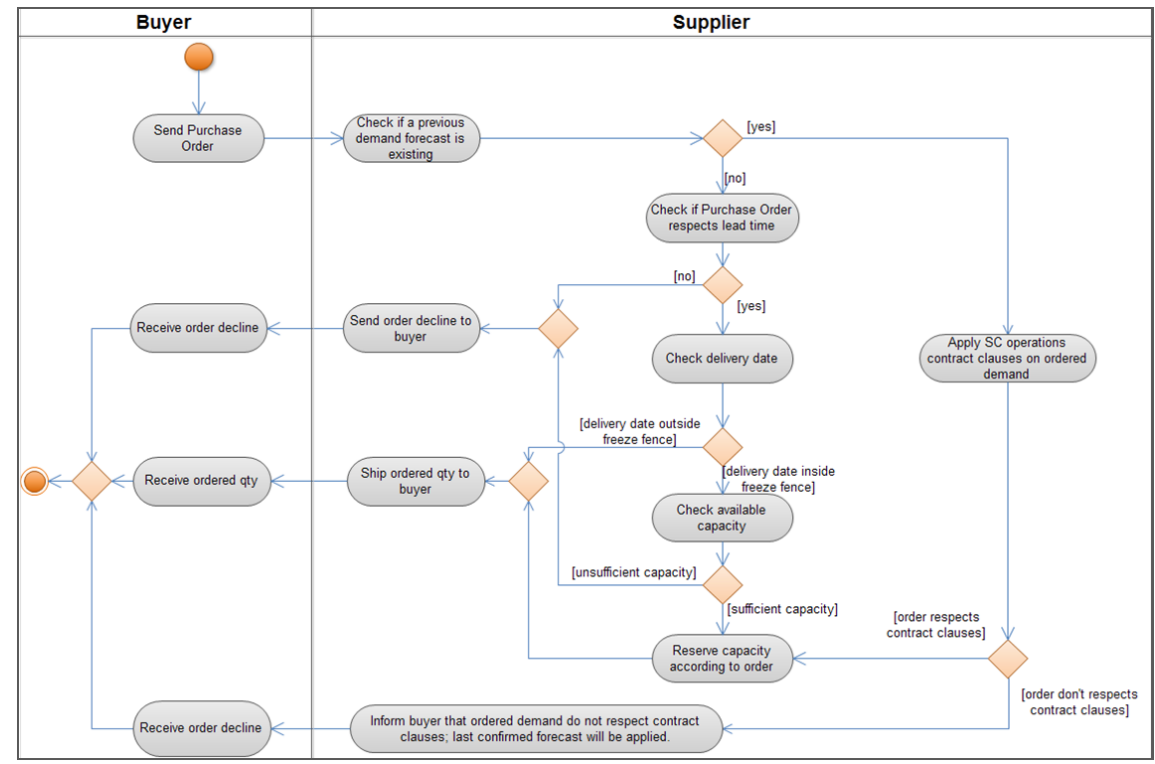

Figure 5: Current Status Model Purchase Order Process. 
Knoblich, Ehm, Heavey, and Williams

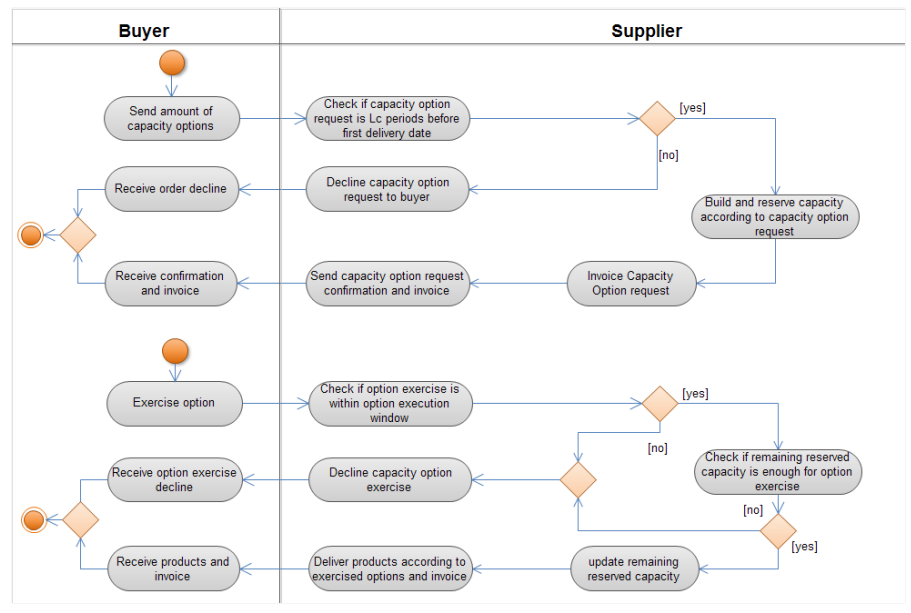

Figure 6: Options based model.

is assumed that the supplier only offers the non-reserved capacity in the spot market. Figure 6 presents a process flow diagram for the implementation of the option based contract in simulation.

\section{CONCLUSIONS AND FUTURE WORK}

This paper highlights challenges faced by semiconductor manufacturers in managing their customer relations, specifically focusing on the issues of long lead times for capacity deployment and low forecasting accuracy, typical of the sector, resulting from the fast pace of technology development. A review of contracting clauses between supplier and customer is given, resulting from a field study and a review of the literature. Models are then presented to compare option based contracts against current contracting practices found in the sector. The paper highlights the importance of semiconductor SC with its unique sectoral characteristics, which has received little attention in the literature. Future work planned is the implementation of the proposed models, parametric optimization and a study of different contract clauses. The standard model will first be used to evaluate the benefit, to the buyer, seller and Supply Chain as a whole, of different adherence levels to the clauses in the standard contract for different forecasting accuracies. Then a study will be carried out to compare the operation of the Supply Chain using the standard model against the options model.

\section{REFERENCES}

Anupindi, R. Bassok, Y. 1998. "Approximations for multiproduct contracts with stochastic demands and business volume discounts: single supplier case". IIE 30:723-734.

Barnes-Schuster, D., Y. Bassok, and R. Anupindi. 2002. "Coordination and Flexibility in Supply Contracts with Options.". Manufacturing \& Service Operations Management 4 (3): 171-207.

Cachon, G. P. 2004. "The Allocation of Inventory Risk in a Supply Chain: Push, Pull, and Advance-Purchase Discount Contracts”. Management Science 50 (2): 222-238.

Cachon, G. P., and F. Zhang. 2006, June. "Procuring Fast Delivery: Sole Sourcing with Information Asymmetry". Manage. Sci. 52 (6): 881-896.

Callioni, G., X. de Montgros, R. Slagmulder, L. N. Van Wassenhove, and L. Wright. 2005, March. "Inventory-Driven Costs". Havard Business Review 83 (3): 135-141.

Cheng, F., M. Ettl, G. Y. Lin, M. Schwarz, and D. D. Yao. 2002. "Flexible Supply Contracts via Options". In IBM T.J. Watson Research.

Edin, A., and B. Hermalin. 2000. "Contract renegotiation and options in agency problems". Journal of Law, Economics, and Organization 16 (2): 395-423. 
Eppen, G. D., and A. V. Iyer. 1997. "Backup Agreements in Fashion Buying-The Value of Upstream Flexibility". Management Science 43 (11): 1469-1484.

Kapuscinski, R., R. Q. Zhang, P. Carbonneau, and B. Moore, R.and Reeves. 2004. "Inventory Decisions in Dell's Supply Chain". Interfaces 34 (3): 191-205.

Katircioglu, K., and G. Gallego. 2011. "A Practical Multi Echelon Inventory Model with Semiconductor Manufacturing Application". In Planning Production and Inventories in the Extended Enterprise, edited by K. G. Kempf, P. Keskinocak, and R. Uzsoy, International Series in Operations Research and Management Science, 133-151. Springer New York.

Kleindorfer, P. R., and D. J. Wu. 2003. "Integrating Long- and Short-Term Contracting via Business-toBusiness Exchanges for Capital-Intensive Industries". Management Science 49 (11): 1597-1615.

Lariviere, M. A., and E. L. Porteus. 2001. "Selling to the Newsvendor: An Analysis of Price-Only Contracts.”. Manufacturing \& Service Operations Management 3 (4): 293-305.

Lee, H., and S. Whang. 2002. "The Impact of the Secondary Market on the Supply Chain". Management Science 48(6) (6): 719-731.

Lee, H. L., V. Padmanabhan, T. A. Taylor, and S. Whang. 2000, April. "Price Protection in the Personal Computer Industry". Manage. Sci. 46:466-482.

Li, C.-L., and P. Kouvelis. 1999. "Flexible and Risk-Sharing Supply Contracts under Price Uncertainty". Management Science 45 (10): 1378-1398.

Lian, Z., and A. Deshmukh. 2009. "Analysis of supply contracts with quantity flexibility". European Journal of Operational Research 196 (2): 526 - 533.

Martinez-de Albeniz, V., and D. Simchi-Levi. 2005. "A Portfolio Approach to Procurement Contracts.". Production \& Operations Management 14 (1): 90 - 114.

Martinez-de Albeniz, V., and D. Simchi-Levi. 2009. "Competition in the Supply Option Market". Operations Research - Baltimore 57:1082-1097.

Pasternack, B. A. 1985. "Optimal Pricing and Return Policies for Perishable Commodities". Marketing Science 4 (2): 166-176.

Schneeweiss, C., K. Zimmer, and M. Zimmermann. 2004. "The design of contracts to coordinate operational interdependencies within the supply chain". International Journal of Production Economics 92 (1): 43 -59 .

Tan, B. 2002. "Managing Manufacturing Risks by Using Capacity Options". The Journal of the Operational Research Society 53 (2): 232-242.

Tsay, A. A. 1999. "The Quantity Flexibility Contract and Supplier-Customer Incentives". Management Science 45 (10): 1339-1358.

Tsay, A. A., S. Nahmias, N. Agrawal, S. Tayur, R. Ganeshan, and M. Magazine. 1999. Chapter 10: Modeling Supply Chain Contracts: A Review Handbooks in Operational Research and Management Science: Quantitative Models For Supply Chain Management. North-Holland, Amsterdam, The Netherlands.

van Delft, C., and J. P. Vial. 2004. "A practical implementation of stochastic programming: an application to the evaluation of option contracts in supply chains". Automatica 40 (5): 743 - 756.

Walsh, P. M., P. A. Williams, and C. Heavey. 2008. "Investigation of rolling horizon flexibility contracts in a supply chain under highly variable stochastic demand.". IMA Journal of Management Mathematics 19 (2): $117-135$.

Wu, D. J., and P. R. Kleindorfer. 2005. "Competitive Options, Supply Contracting, and Electronic Markets". Management Science 51 (3): 452-466.

Wu, D. J., P. R. Kleindorfer, and J. E. Zhang. 2002. "Optimal bidding and contracting strategies for capital-intensive goods". European Journal of Operational Research 137 (3): 657 - 676.

\section{AUTHOR BIOGRAPHIES}

KONSTANZE KNOBLICH is a Ph.D. candidate in the Department of Manufacturing \& Operations Engineering at the University of Limerick, Ireland. She is also working at Infineon Technologies AG in 
the field of supply chain management. She received masters degrees in industrial engineering from the EPF-Ecole dIngnieurs, Sceaux, France and the University of Applied Sciences, Munich, Germany. Her research interests include order management and contract simulation for semiconductor manufacturing networks. Her email address is konstanze.knoblich@infineon.com.

HANS EHM is Principal of Logistics Systems at Infineon Technologies AG. He holds degrees in physics from Germany and a M.S./OSU. In over 20 years in the semiconductor industry he was granted managing and consulting positions at wafer fabrication, assembly \& test, and nowadays for global supply chains on production site, on business unit, and on corporate levels. He is board member of the camLine Holding AG, an IT company for supply and quality chains. He led government funded projects on national and international levels in the context of IT, semiconductor manufacturing, and supply chains among others he initiated the EU/US MIMAC co-operation on capacity modeling. He teaches supply chain management at universities. He is an INFORMS member and on the International Advisory Committee of the MASM conference. His email address is hans.ehm@infineon.com.

CATHAL HEAVEY is a Senior Lecturer of Operations Management in the Department of Manufacturing \& Operations Engineering at the University of Limerick. He is an Industrial Engineering graduate of the National University of Ireland (University College Galway) and holds a M. Eng.Sc. and Ph.D. from the same University. He has published in the areas of queuing and simulation modelling. His research interests includes, simulation modelling of discrete-event systems; modelling and analysis of supply chains and manufacturing systems; process modelling; component-based simulation and decision support systems. His email address is cathal.heavey@ul.ie.

PETER WILLIAMS is a Lecturer of Operations Management in the Department of Manufacturing \& Operations Engineering at the University of Limerick. He holds a Bachelors degree in Engineering from Dublin University (BAI Trinity College Dublin 1977), and a PhD in Engineering from the National University of Ireland (University College Dublin 1984). He has published in the areas of simulation applied to supply-chain and healthcare service delivery problems, as well as socio-technical aspects of supply-chains. His research interests relate to capacity modelling in supply-chain and healthcare service delivery and performance, organisational sense-making and related aspects of culture/governance. His email is peter.williams@ul.ie. 